This item was submitted to Loughborough's Research Repository by the author.

Items in Figshare are protected by copyright, with all rights reserved, unless otherwise indicated.

\title{
Polycaprolactone multicore-matrix particle for the simultaneous encapsulation of hydrophilic and hydrophobic compounds produced by membrane emulsification and solvent diffusion processes
}

\section{PLEASE CITE THE PUBLISHED VERSION}

http://dx.doi.org/10.1016/j.colsurfb.2015.06.071

\section{PUBLISHER}

(C) Elsevier

\section{VERSION}

AM (Accepted Manuscript)

\section{PUBLISHER STATEMENT}

This work is made available according to the conditions of the Creative Commons Attribution-NonCommercialNoDerivatives 4.0 International (CC BY-NC-ND 4.0) licence. Full details of this licence are available at: https://creativecommons.org/licenses/by-nc-nd/4.0/

\section{LICENCE}

CC BY-NC-ND 4.0

\section{REPOSITORY RECORD}

Imbrogno, A., Marijana M. Dragosavac, Emma Piacentini, Goran T. Vladisavljevic, R.G. Holdich, and L. Giorno. 2015. "Polycaprolactone Multicore-matrix Particle for the Simultaneous Encapsulation of Hydrophilic and Hydrophobic Compounds Produced by Membrane Emulsification and Solvent Diffusion Processes". figshare. https://hdl.handle.net/2134/18713. 


\title{
Polycaprolactone multicore-matrix particle for the simultaneous encapsulation of hydrophilic and
} hydrophobic compounds produced by membrane emulsification and solvent diffusion processes

\author{
Imbrogno A. ${ }^{\mathrm{a}, \mathrm{b}}$, Dragosavac M.M ${ }^{\mathrm{c}, *}$, Piacentini E. ${ }^{\mathrm{a}}$, , Vladisavljević G.T. ${ }^{\mathrm{c}}$, Holdich R.G. ${ }^{\mathrm{c}}$, Giorno L ${ }^{\mathrm{a}}$. \\ ${ }^{a}$ Institute on Membrane Technology, National Research Council, ITM-CNR, Via P. Bucci 17/C at \\ University of Calabria, 87036 Rende (CS), Italy \\ ${ }^{\mathrm{b}}$ Dipartimento di Ingegneria per l'Ambiente e il Territorio e Ingegneria Chimica, University of Calabria, Via \\ P. Bucci 42/A, 87036 Rende (CS), Italy \\ ${ }^{\mathrm{c}}$ Department of Chemical Engineering, Loughborough University, Leicestershire LE11 3TU, UK
}

\begin{abstract}
*Corresponding author: Chemical Engineering Department, Loughborough University, Loughborough, LE113TU, UK, Phone: +44 (0) 1509222 501, Email: m.dragosavac@lboro.ac.uk
\end{abstract}

\begin{abstract}
Co-encapsulation of drugs in the same carrier, as well as the development of microencapsulation processes for biomolecules using mild operating conditions, and the production of particles with tailored size and uniformity are major challenges for encapsulation technologies. In the present work, a suitable method consisting of the combination of membrane emulsification with solvent diffusion is reported for the production of multi-core matrix particles with tailored size and potential application in multi-therapies. In the emulsification step, the production of a W/O/W emulsion was carried out using a batch Dispersion Cell for formulation testing and subsequently a continuous azimuthally oscillating membrane emulsification system for the scaling-up of the process to higher capacities. In both cases precise and gentle control of droplet size and uniformity of the $\mathrm{W} / \mathrm{O} / \mathrm{W}$ emulsion was achieved, preserving the encapsulation of the drug model within the droplet. Multi-core matrix particles were produced in a post emulsification step using solvent diffusion. The compartmentalized structure of the multicore-matrix particle combined with the different chemical properties of polycaprolactone (matrix material) and fish gelatin (core material) was tested for the simultaneous encapsulation of hydrophilic (copper ions) and hydrophobic ( $\alpha$-tocopherol) test components.
\end{abstract}


The best operating conditions for the solidification of the particles to achieve the highest encapsulation efficiency of copper ions and $\alpha$-tocopherol of $99( \pm 4) \%$ and $93( \pm 6) \%$ respectively were found. The multicore matrix particle produced in this work demonstrates good potential as a co-loaded delivery system.

\section{Keywords}

Membrane emulsification scale up; W/O/W emulsion; Co-encapsulation; Uniform spherical microcapsules;

High encapsulation efficiency, Vitamin E

\section{Highlights}

- Novel azimuthally oscillating membrane emulsification system has been used for the production of highly uniform $\mathrm{W}_{1} / \mathrm{O} / \mathrm{W}_{2}$ emulsions

- Emulsion dilution promoted the solvent removal allowing the polymer solidification

- Uniform solid multi-core poly-caprolactone particles were produced

- Particle morphology and encapsulation efficiency were controlled by the solidification step

- Encapsulation efficiency of both copper ions and $\alpha$-tocopherol was achieved 


\section{Introduction}

Microencapsulation is defined as a process to entrap material in a coating which isolates and protects the material from the external environment. The design of appropriate micro and nanostructured encapsulation systems, such as W/O/W emulsions, spheres, beads and capsules, is of great interest in the pharmaceutical field for 1) the improvement of drug bioavailability, 2) protection of drug from environmental conditions, 3) controlled release, 4) reduction of side effects and frequency of administration [1]. Microcapsules (particle diameter in the range between $3 \mu \mathrm{m}$ and $800 \mu \mathrm{m}$ ) consist of an inner core and a shell, or a matrix that covers and protects the core. On the basis of particle morphology microcapsules are classified as: i) reservoir type (core-shell capsule) which is composed of a single core surrounded by a continuous shell; ii) matrix type (poly- or multiple-core particle) which is characterized by the presence of several reservoir chambers dispersed in a polymer matrix [2].

In this study, the combination of two biopolymers poly-caprolactone (PCL) and fish gelatin (FG), both FDA approved materials, with different chemical properties is proposed for the construction of novel multicorematrix particles for drug encapsulation. The polymer matrix is composed of poly-caprolactone (PCL) which is hydrophobic biodegradable polyester suitable for the encapsulation of poorly water soluble compounds. PCL is an advantageous material for drug encapsulation owing to its high permeability to small drug molecules and its negligible tendency to generate an acidic environment during the degradation process as compared to polylactids and polyglicolids, a problem that contributes to the generation of inflammatory reactions [3]. The multicore in the particle is composed of cold water fish gelatin (FG), which is a water soluble natural polymer widely used in various industries for the capsule manufacture. In this study, FG was used alternatively as core material owing to its solubility at ambient temperature which makes it suitable for the encapsulation of heat sensitive compounds. Moreover, it is also a good alternative to bovine or pig gelatin for oral formulations as it is acceptable to ethnic groups that do not consume pig or cow products [4]. The compartmentalized structure of the multicore-matrix particle combined with the different chemical properties of PCL and FG was investigated to co-encapsulate compounds with different water solubility in the same carrier. This is potentiality of great interest for application in multi-therapies as co-administration of two or more drugs has been demonstrated to improve the therapeutic efficiency in clinical practice for the 
treatment of complex diseases such as cancer, diabetes, immune-inflammatory disorders, bacterial and viral infections [5]. Co-encapsulation of multiple drugs has several potential advantages compared with single drug encapsulation, including i) synergistic effects, ii) suppressed drug resistance, and iii) the ability to tune the dosage of various drugs to the level of a single carrier [6]. Some examples of carriers at micro- and nanoscale, such as liposomes, micelles, polymer-drug conjugates and core-shell capsules have been developed for co-delivery of multiple drugs [7-10]. Nevertheless, to date, combining drugs into a single carrier is still a challenge for encapsulation technologies.

Various methodologies classified as physical: fluidized bed-coating; spray drying and spray cooling, or chemical: coacervation; interfacial polymerization and solvent diffusion/evaporation, are available for the encapsulation of core material [11]. Core-shell capsules are usually obtained from W/O or O/W emulsions by coacervation or interfacial polymerization $[12,13]$. W/O/W emulsions are usually required for the coencapsulation of hydrophilic compounds within a hydrophobic polymer matrix, such as biodegradable polyesters, and multi-core matrix particles are obtained after removal of the solvent either by evaporation, or extraction $[14,15]$.

The choice of the emulsification process is a key issue in the encapsulation as it influences directly the final size, and size distribution, of the solid particles. Some important challenges are required for the advancement of microencapsulation technologies in engineering microcapsules with improved functional and structured properties:

i) achieving precise control of particle size and size distribution in the emulsification step while maintaining the incorporation of biomolecules without affecting their activity; the distribution in the body; the interaction with living cells as well as the drug release kinetics of the solid particles are greatly influenced by their size and uniformity [1], and

ii) maintaining the performance of a good emulsification step when the process is transferred from the laboratory scale to a larger throughput scale [16].

The commonly encountered emulsification devices such as: high pressure homogenizers, ultrasonication and rotor-stator systems, are often not suitable for these requirements. Therefore, modification of the laboratory method, or the development of new techniques, is necessary [16]. Membrane emulsification is an extremely effective technique to meet these requirements.The formation of highly uniform droplets [17] as well as the 
low energy density of the process compared to conventional mechanical methods [18], provides the encapsulation of labile molecules in particulate systems with controlled size keeping their quality and functionality. The mild conditions of membrane emulsification are especially useful when the microencapsulation process involves the preparation of a W/O/W emulsion as an initial liquid phase.This kind of emulsion is highly thermodynamically unstable and emulsion breakdown can occur easily in the high shear stress conditions. Another additional advantage of membrane emulsification is the easy process scaleup which can be carried out, keeping the performance demonstrated at the laboratory scale [19]. So far, membrane emulsification has been investigated for microencapsulation of water soluble and lipophilic drugs within W/O/W emulsions such as: ethanol-oil-water E/O/W; and water-oil-water W/O/W [20,21] or within microspheres and capsules produced in most cases by coacervation, interfacial polymerization and solvent evaporation [22-25].

In the present work, an alternative strategy consisting of the combination of membrane emulsification followed by solvent diffusion is investigated for the production of a co-loaded delivery system with potential application in multi-therapies. The fast solidification of the polymer, which is correlated with the solvent diffusion rate, achieves high encapsulation efficiency of the multi-core matrix particle produced by the solidification of the $\mathrm{W}_{1} / \mathrm{O} / \mathrm{W}_{2}$ emulsion. The emulsion production was initially investigated at a batch scale to determine the optimal conditions followed by the process scale using an azimuthal oscillating membrane emulsification system. The latter is a recently introduced continuous emulsification system which provides: i) achievement of high flux suitable for an industrial setting; ii) produces highly concentrated uniform emulsions in a continuous mode and short processing time; and iii) employs low shear conditions in the bulk of the product stream to preserve the activity of encapsulated labile molecules. In this study the potential benefits for the production of a fragile system, such as $\mathrm{W}_{1} / \mathrm{O} / \mathrm{W}_{2}$ emulsions, keeping the uniformity of the droplets and high throughput, is demonstrated for the first time.

\section{Material and methods}

\section{Chemicals}


Poly-caprolactone (MW 14 kDa, 16-30\% w/v, Sigma-Aldrich, UK) and $\alpha$-tocopherol (vitamin E, Sigma Aldrich, MW $430.71 \mathrm{~g} \mathrm{~mol}^{-1}$, $5000 \mathrm{ppm}$ ) were dissolved in dichloromethane (DCM, Sigma-Aldrich, UK) and were used as organic phase (O) for the preparation of $\mathrm{O} / \mathrm{W}_{2}$ and $\mathrm{W}_{1} / \mathrm{O} / \mathrm{W}_{2}$ emulsion. Cold water-fish gelatin (MW $60 \mathrm{kDa}, 5-20 \% \mathrm{wt} / \mathrm{v}$ ) was used as stabilizer in the inner $\left(\mathrm{W}_{1}\right)$ aqueous phase containing $\mathrm{Cu}(\mathrm{II})$ ions (MW 65 g/mol, 2000 ppm) in the form of copper sulphate (Fisher Scientific, UK). Ethanol (SigmaAldrich, UK) was used for the extraction of $\alpha$-tocopherol from the solid particles after the dissolution of the particles in DCM as previously reported by Byun et. al [26]. Poly-vinyl alcohol (PVA, MW 13-23 kDa, 1\% $\mathrm{wt} / \mathrm{v}$ ) was used as emulsifier for the preparation of $\mathrm{O} / \mathrm{W}_{2}$ and $\mathrm{W}_{1} / \mathrm{O} / \mathrm{W}_{2}$ emulsion and the external aqueous phase was previously saturated with DCM to avoid the diffusion of the solvent during the emulsification process. Sodium dodecyl sulphate (SDS, MW 288 Da, 2\% wt/v, Sigma-Aldrich, UK) or PVA (1 \% wt/v) were used as stabilizers in the aqueous phase during the solvent diffusion process. All the aqueous solutions were prepared using ultrapure water.

\section{Experiments carried out and operating conditions}

The preparation of $\mathrm{W}_{1} / \mathrm{O} / \mathrm{W}_{2}$ emulsion was carried out in two steps. The primary $\mathrm{W}_{1} / \mathrm{O}$ emulsion was prepared using a mechanical homogenizer (Ultra-Turrax ${ }^{\circledR}$, model T10, IKA Works, USA) for 3 minutes at $30000 \mathrm{rpm}$ in order to obtain small and highly dispersed water droplets followed by injection through the porous membrane to produce a $\mathrm{W}_{1} / \mathrm{O} / \mathrm{W}_{2}$ emulsion. The chemical composition of the double emulsion is reported in Figure 1. $\mathrm{W}_{1} / \mathrm{O} / \mathrm{W}_{2}$ emulsion-solvent diffusion process was used for the production of the solid multi-core matrix. $\mathrm{W}_{1} / \mathrm{O} / \mathrm{W}_{2}$ emulsion produced by membrane emulsification was mixed with higher volume of water $\left(V_{s d}\right)$ compared with the theoretical volume $\left(V_{t h}\right)$ containing the stabilizer (2\% wt $/ \mathrm{v}$ SDS or $1 \% \mathrm{wt} / \mathrm{v}$ PVA). The latter is the volume of water required to ensure the complete diffusion (removal) of solvent contained within the dispersed phase $\left(\mathrm{W}_{1} / \mathrm{O} / \mathrm{W}_{2}\right.$ emulsion). Considering the percentage of the dispersed phase emulsified $(6 \% \mathrm{v} / \mathrm{v})$, the percentage of the inner aqueous phase $\left(\mathrm{W}_{1}, 10 \% \mathrm{v} / \mathrm{v}\right)$ and the polymer concentration (30\% w/v), DCM volume was $4.18 \mathrm{ml}$ and the theoretical volume of water $\left(V_{t h}\right)$ was $278 \mathrm{ml}$. The latter was calculated from the solubility of dichloromethane in water $(2 \%, w / v)$ as reported by Imbrogno A. et al. [27]. The produced solid particles were recovered by filtration washed with deionized water and freeze dried. 
In order to identify the appropriate process parameters (injection flux of the dispersed phase and shear stress) during membrane emulsification, preliminary experiments were carried out using a Dispersion Cell for the preparation of $\mathrm{O} / \mathrm{W}_{2}$ emulsion. The best operating conditions to produce the most uniform $\mathrm{W}_{1} / \mathrm{O} / \mathrm{W}_{2}$ emulsions are reported in Figure 1. The influence of process parameters on droplet size and size distribution were evaluated for the scaling-up of the process using the azimuthally oscillating membrane emulsification system.

Inorganic salts have been previously used as a marker to monitor encapsulation and release $[28,29]$ and in this work copper ions (MW=63.5 $\mathrm{g} \mathrm{mol}^{-1}$ ) were used as the hydrophilic marker to mimic a small hydrophilic drug molecule. Atomic Adsorption Septroscopy (AAS, SpectrAA 55B, Varian, UK, operating at wavelength of $324.8 \mathrm{~nm}$ ) was used to accurately measure the copper concentrations. $\alpha$-tocopherol (a fat-soluble vitamin, with negligible water solubility of $0.021 \mathrm{~g} \mathrm{~L}^{-1}$ ) [30] was used as hydrophobic drug model.

\section{Membrane emulsification equipment}

A flat sheet micro-sieve stainless steel membrane with $10 \mu \mathrm{m}$ circular pore size of an emulsification active area of $1.85 \mathrm{~cm}^{2}$ and a surface porosity of $0.19 \%$ was used for the preparation of the emulsion using the Dispersion Cell. An illustration of the system is given in Figure 1A. The membrane was fitted under the paddle stirrer and the rotation speed of the stirrer is regulated by selecting the appropriate voltage in the range from 420 to 1550 rpm corresponding to a shear stress in the range from 2.2 to $11 \mathrm{~Pa}$. The dispersed phase was injected through the membrane using a syringe pump (ALADDIN2-220, World Precision Instruments, UK) and the flow rate was varied from $0.7 \mathrm{ml} \mathrm{min}^{-1}$ to $2.5 \mathrm{ml} \mathrm{min}{ }^{-1}$, corresponding to a dispersed phase flux between 216 and $810 \mathrm{~L} \mathrm{~h}^{-1} \mathrm{~m}^{-2}$. A tubular micro-sieve stainless steel membrane with a pore size of $15 \mu \mathrm{m}$ distributed over a membrane area of $52 \mathrm{~cm}^{2}$ and with a surface porosity of $0.44 \%$ was used for the preparation of the emulsions by an azimuthally oscillating membrane emulsification system. A schematic representation of this system is illustrated in Figure 1B. The shear stress is generated by twisting the membrane rather than by flowing the continuous phase, since the cross-flow velocity is negligible. The oscillation of the membrane is generated by a servo motor fitted to the membrane module. The amplitude and frequency of the oscillation can be regulated using a digital control panel. The dispersed phase was injected with the syringe pump radially through the porous membrane wall and droplets are formed by 
moving into the continuous phase. The flow rate of the pump was varied between 2 and $18.3 \mathrm{ml} \mathrm{min}^{-1}$ corresponding to a dispersed phase flux between 23 and $216 \mathrm{~L} \mathrm{~h}^{-1} \mathrm{~m}^{-2}$. The continuous phase was pumped using a peristaltic pump (Watson-Marlow-Bredel Pump 101U/R, UK) upwards into the annulus between the stationary vessel and the oscillating membrane and the emulsion was collected into a tank from the top of the vessel. The amplitude varied between 1.5 and $3.5 \mathrm{~mm}$ while the frequency of oscillation was between 15 and $50 \mathrm{~Hz}$, corresponding to shear stress in a range of $1 \mathrm{~Pa}$ to $6 \mathrm{~Pa}$ (Equation 3). The Dispersion Cell, azimuthally oscillating membrane emulsification device and the membranes were supplied by Micropore Technologies Ltd. (Derby, UK).

\section{Modelling of the droplet size}

The produced droplets diameter $(x)$ can be predicted from a force balance and it was calculated as reported in the Equation 1 [31,32]:

$x=\frac{\sqrt{18 \tau^{2} r_{p}^{2}+2 \sqrt{81 \tau^{4} r_{p}^{4}+4 r_{p}^{2} \tau^{2} \gamma^{2}}}}{3 \tau}$

where $r_{p}[\mathrm{~m}]$ is the pore radius, $\tau[\mathrm{Pa}]$ is the shear stress and $\gamma\left[\mathrm{N} \mathrm{m}^{-1}\right]$ is the interfacial tension. In the Dispersion Cell the shear stress $(\tau)$ at the surface of the membrane depends on the angular velocity $(\omega)\left[\mathrm{s}^{-1}\right]$ of the stirrer and it was calculated using the Equation 2:

$$
\tau_{\max }=0.825 \mu_{c} \omega r_{\text {trans }} \frac{1}{\delta}
$$

where $\mu_{c}$ [Pa s] is the continuous phase viscosity, $r_{\text {trans }}$ is the transitional radius and $\delta$ is the boundary layer thickness $\delta=\sqrt{\mu_{c} / \omega \rho_{c}}$.

In the case of the oscillating membrane emulsification system, the oscillation of the membrane was applied in a sinusoidal way, therefore the maximum shear $\left(\tau_{\max }\right)[\mathrm{Pa}]$ was calculated using the Equation 3 [33]:

$$
\tau_{\max }=2 a(\pi f)^{1.5}\left(\mu_{c} \rho_{c}\right)^{0.5}
$$

where $\rho_{c}\left[\mathrm{~kg} \mathrm{~m}^{-3}\right]$ the continuous phase density, $f\left[\mathrm{~s}^{-1}\right]$ is the frequency and $a[\mathrm{~m}]$ is the amplitude of the membrane oscillation. 


\section{Particle size analysis and morphology}

Solid particle size and size distribution were measured using laser diffraction (Mastersizer 2000, Malvern Instruments, UK). To confirm the Mastersizer measurements images were taken using a Leitz Ergolux optical microscope with an attached Pulnix TM-6CN monochrome camera. The mean particle size was expressed as the volume median diameter $D(v, 0.5)$ and the span value $($ span $=(D(v, 0.9) \times D(v, 0.1)) / D(v$, 0.5)) was used to express the degree of uniformity. Three samples were analyzed for each experiment and the reported results are the average of three different experiments. The morphology of the particles was observed by scanning electron microscopy operated at $2.6 \mathrm{kV}$ (Cambridge Instruments, UK).

\section{Copper extraction and encapsulation efficiency}

The encapsulation of copper ions (Cu(II)) was investigated immediately after the emulsification process $\left(E E_{\text {WOW }}\right)$ and by an extraction method after particle disruption $\left(E E_{p}\right)$.

According to the previous work of Dragosavac et al. [29], the encapsulation efficiency ( $\left.E E_{W O W}\right)$ of copper, $\mathrm{Cu}(\mathrm{II})$, into the $\mathrm{W}_{1} / \mathrm{O} / \mathrm{W}_{2}$ emulsion was calculated using Equation 4 :

$$
E E_{W O W}=\left(1-\frac{C_{o}}{C_{i}} \frac{1-\Phi_{W O W}}{\Phi_{W O W} \Phi_{W O}}\right) \times 100(\%)
$$

where $C_{i}$ is the initial $\mathrm{Cu}(\mathrm{II})$ concentration in the inner water phase, $\Phi_{W O}$ is the volume fraction of the inner aqueous phase emulsified in the primary W/O emulsion, $\Phi_{\text {Wow }}$ is the volume fraction of the primary W/O emulsion emulsified in the $\mathrm{W} / \mathrm{O} / \mathrm{W}$ emulsion and $C_{O}$ is the $\mathrm{Cu}(\mathrm{II})$ concentration in the outer water phase at $t$ $=0$ measured by AAS. In this study $C_{i}$ was $2000 \mathrm{ppm}, \Phi_{\text {wo }}$ was changed in the range between 0.1 and 0.3 and $\Phi_{\text {WOW }}$ was 0.06 . The maximum concentration of $\mathrm{Cu}(\mathrm{II})$ in the $\mathrm{W}_{1} / \mathrm{O} / \mathrm{W}_{2}$ emulsion corresponding to infinitely long release time $\left(C_{\infty}\right)$ was calculated from the Equation 4 as $C_{O}$ value for $E E_{W O W}=0$ and it was in the range between 13 and 38 ppm.

The encapsulation efficiency of the solidified particles was determined by copper extraction after particle disruption. In this case, $100 \mathrm{mg}$ of powder were dissolved in $4 \mathrm{ml}$ of DCM, after which $6 \mathrm{ml}$ of water was added to the organic phase and the mixture was stirred gently over-night in order to extract the copper ions 
into the aqueous phase. The sample was centrifuged at $3000 \mathrm{rpm}$ and the concentration of copper ions in the aqueous phase was determined by AAS.

The encapsulation efficiency of the particles $\left(E E_{p}\right)$ was calculated as the ratio between the mass of copper measured by AAS to the total mass of copper entrapped into the powder (Equation 5). The latter was calculated taking into account the maximum $\mathrm{Cu}(\mathrm{II})$ concentration in the $\mathrm{W}_{1} / \mathrm{O} / \mathrm{W}_{2}$ emulsion immediately after the emulsification process $\left(\mathrm{C}_{\infty}\right)$.

$$
E E_{p}=\frac{\text { mass of } \mathrm{Cu}(\mathrm{II}) \text { extracted }(\mathrm{g})}{\text { mass of } \mathrm{Cu}(\mathrm{II}) \text { added }(\mathrm{g})} \times 100
$$

The drug loading $(D L)$ was calculated as the ratio of the drug encapsulated to the total mass of powder:

$$
D L=\frac{\text { mass of drug extracted }(g)}{\text { mass of powder }(g)} \times 100
$$

The theoretical drug loading was calculated considering the theoretical drug content into the mass of powder.

$\alpha$-tocopherol extraction and encapsulation efficiency

Since $\alpha$-tocopherol is not soluble in water, the encapsulation efficiency ( $\left.E E_{W O W}\right)$ was assumed to be $100 \%$ for the $\mathrm{W}_{1} / \mathrm{O} / \mathrm{W}_{2}$ emulsion and it was measured only for the solidified particles. For the extraction of $\alpha$ tocopherol, $60 \mathrm{mg}$ of powder was dissolved in $4 \mathrm{ml}$ of DCM and the extraction of $\alpha$-tocopherol was performed by adding a known volume of ethanol into DCM [26]. The latter was quickly removed by evaporation with a consequent precipitation of the PCL. The suspension was centrifuged at $3000 \mathrm{rpm}$ and the vitamin content in the supernatant was analyzed by UV/VS spectroscopy (operating at the wavelength of 285 $\mathrm{nm})$. The encapsulation efficiency $\left(E E_{p}\right)$ of $\alpha$-tocopherol was calculated using the Equation 5 where the mass of $\mathrm{Cu}(\mathrm{II})$ was substituted with the mass of $\alpha$-tocopherol.

\section{Results and discussion}

Influence of process parameters on the production of $\mathrm{O} / \mathrm{W}_{2}$ emulsion at batch scale 
The effect of the injection flux on droplet size and size distribution is reported in Figure 2A using 16\% and $30 \%$ of PCL dissolved in DCM. For the constant shear of 8Pa an increase of droplet size from $42 \mu \mathrm{m}$ to 62 $\mu \mathrm{m}$ as well as the increase of span from 0.30 to 0.45 was observed when the injection flux was increased from 216 to $810 \mathrm{~L} \mathrm{~h}^{-1} \mathrm{~m}^{-2}$. The increase of the dispersed phase flux is correlated with a faster increase of droplet growth at the pore level resulting in the formation of larger droplets before the detachment [34].

Figure 2B reports the effect of shear stress at constant injection flux $\left(216 \mathrm{~L} \mathrm{~h}^{-1} \mathrm{~m}^{-2}\right)$ on droplet size and size distribution. A decrease of droplet size in the range from $112 \mu \mathrm{m}$ to $40 \mu \mathrm{m}$ was observed with the increase of the shear stress in a range from 2.2 Pa to $11 \mathrm{~Pa}$ accompanied with span reduction from 0.38 to 0.30 . The decrease of droplet size is correlated with an increase of the drag force acting on the droplets which were detached from the membrane sooner. This effect is more significant when shear stress lower than 6 Pa was applied while the median drop size was virtually independent on the drag force at shear stresses higher than 6 Pa. The decrease of droplet size is in good accordance with the predicted model even though the experimental values were lower than the predicted values of the model. The latter can be affected by the empirical determination of the interfacial tension. The Du Noüy ring method was used [35]. The measurements were affected by the quick evaporation of DCM at the air/water interface and the experimental error of the measurements of the interfacial tension influence the fitting of the predicted droplet size of the model to the experimental data. The difference observed in terms of droplet size as a function of PCL concentration (Figure $2 \mathrm{~A}$ and $\mathrm{B}$ ) is related to the increase of the interfacial tension from $3.4 \pm 0.3$ to $4.2 \pm$ $0.3 \mathrm{mN} \mathrm{m}^{-1}$ as the PCL concentration increased from $16 \%$ to $30 \%$. Larger droplets were produced when $30 \%$ of PCL was used because the higher interfacial tension keeps the droplet adhesion at the edge of the pore retarding the detachment. The production of the $\mathrm{W}_{1} / \mathrm{O} / \mathrm{W}_{2}$ emulsion was carried out using an injection flux of $216 \mathrm{~L} \mathrm{~h}^{-1} \mathrm{~m}^{-2}$ and a shear stress of $11 \mathrm{~Pa}$ as the best uniformity was achieved in these conditions. Droplets with a mean size of $41 \pm 2 \mu \mathrm{m}$ and a span of $0.30 \pm 0.02$ were obtained.

\section{Influence of the chemical composition on the stability of the $\mathrm{W}_{1} / \mathrm{O} / \mathrm{W}_{2}$ emulsion}

The composition of the $\mathrm{W} / \mathrm{O} / \mathrm{W}$ emulsion is of great importance since the type and concentration of surfactant, as well as the nature of the oil phase, affects the stability of the $\mathrm{W}_{1} / \mathrm{O} / \mathrm{W}_{2}$ emulsion. PCL is not a good emulsifier as demonstrated by the high value of interfacial tension $(20 \pm 3 \mathrm{mN} / \mathrm{m})$ measured at the 
water/organic phase interface. The use of PCL without any other emulsifier leads to the quick separation of the two phases [36]. Cold water fish gelatin was added in the aqueous phase in order to retard the phase separation due to its surface active properties and viscosity. The addition of FG in the aqueous phase resulted in the reduction of the interfacial tension by almost $70 \%$ independent of the polymer concentration. The latter is due to the presence of hydrophobic chains responsible for interfacial adsorption at the water/oil interface. The increase of fish gelatin concentration in a range of $5 \%$ to $20 \%$ did not further reduce the interfacial tension which appeared to reach an equilibrium value at $6( \pm 0.3 \mathrm{mN} / \mathrm{m})$. The same trend was observed by Surh et al. [37]. The increase of FG concentration did not increase the encapsulation efficiency of hydrophilic molecule or stability of inner water droplets but reduced the particle sphericity therefore in this study the concentration of FG in the inner aqueous phase was kept constant at 5\%.The instability of a $\mathrm{W}_{1} / \mathrm{O} / \mathrm{W}_{2}$ emulsion can be affected also by the composition of the organic phase, which acts as a separating film modulating the internal coalescence and diffusion of water [38]. In Figure 3 the microphotographs of the double emulsions produced with different PCL concentrations (16-30\%) taken immediately after the production are reported. Coalescence of the inner aqueous droplets occurred when PCL concentration was $16 \%$ and $20 \%$ as indicated by the size and the low concentration of the inner water droplets. However, stable concentrated droplets of inner aqueous phase were observed when $30 \%$ of PCL was used. The increase of PCL concentration increased the viscosity of the liquid film where the aqueous droplets are dispersed and, consequently, their coalescence was reduced. Taking into account these results, the $\mathrm{W}_{1} / \mathrm{O} / \mathrm{W}_{2}$ emulsion containing $5 \%$ of FG in the inner aqueous phase $\left(W_{1}\right)$ and 30\% of PCL in the organic phase $(O)$ was used for the production of the solid particles.

Scaling up of the emulsion production by oscillating membrane emulsification

An important requirement for a particle manufacturing process is the possibility to produce particles with tailored size and uniformity at high throughput (possibly continuously), under low shear conditions and in an easy to scale way. Oscillating membrane emulsification achieves high flux suitable for an industrial setting preserving at the same time the uniformity of the emulsion and keeping low shear conditions in the bulk of the product stream. Figure 4 reports the droplet size of $\mathrm{O} / \mathrm{W}_{2}$ emulsion as a function of the shear stress. The influence of the shear stress was studied at two injection flow rates $\left(1\right.$ and $4 \mathrm{ml} \mathrm{min}^{-1}$ corresponding to 
injection fluxes of 12 and $46 \mathrm{~L} \mathrm{~h}^{-1} \mathrm{~m}^{-2}$ ) in order to compare the droplet size with the predicted value of the model. Mean droplet size decreased from $90 \mu \mathrm{m}$ to $49 \mu \mathrm{m}$ and from $112 \mu \mathrm{m}$ to $59 \mu \mathrm{m}$ when shear stress was increased in a range between $1 \mathrm{~Pa}$ and $6 \mathrm{~Pa}$ and using the injection flux of 12 and $46 \mathrm{~L} \mathrm{~h}^{-1} \mathrm{~m}^{-2}$ respectively. The droplet size produced at low injection flux $\left(12 \mathrm{~L} \mathrm{~h}^{-1} \mathrm{~m}^{-2}\right)$ are closer to the predicted values of the model. This is because the increase of the flow rate is correlated with an increase of the dispersed phase flux and the contribution of this parameter to the formed droplet size is not considered in the calculation of the model [39]. A widening of size distribution was observed when the dispersed phase was injected at low flux (12 L $\mathrm{h}^{-1} \mathrm{~m}^{-2}$ ) keeping high shear stress (5-6 Pa). In Figure 4B the emulsion produced at a shear stress of $6 \mathrm{~Pa}$ and low injection flux appears to be bimodal and small droplets with a mean size of $12 \mu \mathrm{m}$ were formed as well as larger droplets. The formation of a polydispersed emulsion when low dispersed phase flux is used in the combination with the high shear can be attributed to the membrane type used as previously seen by Holdich et.al [31]. The sieve membrane has straight through pores which means that it is easier for a pressure pulse to pass through the membrane from the receiving side where the continuous phase is present and into the side of the membrane where the dispersed phase is present. This may cause mixing around the pore on the dispersed phase side of the membrane leading to drop sizes that are much smaller than would be expected from the prevailing conditions of wall shear, a situation similar to what occurs during premix emulsification [31]. Increasing the flux of the dispersed phase to $46 \mathrm{~L} \mathrm{~h}^{-1} \mathrm{~m}^{-2}$ the mixing of the phases was avoided and uniform droplets with a span value in a range of 0.30 and 0.39 were produced in a range of shear stress of 1 Pa to $6 \mathrm{~Pa}$. At shear stress above $5 \mathrm{~Pa}$ the droplet size remained constant at $57 \pm 2 \mu \mathrm{m}$. The same trend was observed at batch scale and the range of shear stresses is quite similar (i.e. above $6 \mathrm{~Pa}$ ).

Taking into account these results, the influence of the dispersed phase flux on droplet size and size distribution (Figure 5) of $\mathrm{W}_{1} / \mathrm{O} / \mathrm{W}_{2}$ emulsion was investigated using a shear stress of $5 \mathrm{~Pa}$ and the dispersed phase flux was increased from 23 to $216 \mathrm{~L} \mathrm{~h}^{-1} \mathrm{~m}^{-2}$. This provided an increase of the dispersed phase volume concentration from $4 \%$ to $35 \%$ in a single pass of the continuous phase flowing inside the module at constant flow rate of $53 \mathrm{ml} \mathrm{min}^{-1}$. Uniform $\mathrm{W}_{1} / \mathrm{O} / \mathrm{W}_{2}$ emulsion with a content of dispersed phase of 35 vol\% were produced at the same fluid-dynamic conditions optimized at the batch scale $\left(J_{d p}=216 \mathrm{~L} \mathrm{~h}^{-1} \mathrm{~m}^{-2} ; \tau=5 \mathrm{~Pa}\right)$. Such finding suggests that future formulations and optimal conditions btained on the Dispersion Cell, where small volumes are required, can be translated successfully to the azimuthal oscillating membrane 
emulsification system. Uniform droplets with a mean size of $59 \mu \mathrm{m}$ (which corresponds to solid particles with a mean size of $47 \mu \mathrm{m}$ ) and a span value between 0.31 and 0.36 were produced in the range of flux studied. The results demonstrated that the “dripping” regime was dominant for the range of fluxes studied. In this regime, the drag force imparted by the oscillating movement of the membrane and the surface tension force are the dominant forces affecting the droplet size, therefore, the inertial contribution from the dispersed phase flux was negligible to the droplet size [40].

\section{Influence of process conditions used in the solidification step on particle morphology}

The solidification of the multicore-matrix particles was carried out using the solvent diffusion process. Solid particles with a mean size of $29 \pm 1 \mu \mathrm{m}$ and a span value of $0.30 \pm 0.02$ were produced after the solidification of the PCL and a particle shrinkage of $29 \%$ was observed. In the study the influence of: i) volume of water used for the solvent diffusion; ii) type of stabilizers used; iii) amount of inner aqueous phase ( $\left.\Phi_{W O}\right)$ in W/O/W emulsion on final particle morphology are reported.

\section{i) Effect of the volume of water used for solvent diffusion}

The solidification rate of the droplets can be controlled by changing the volume of water (containing stabilizer) used for solvent diffusion $\left(V_{s d}\right)$ with respect to the theoretical volume $\left(V_{t h}\right)$. In Table $1(\mathrm{~A})$ the experimental conditions used for the solidification of the multi-core matrix particles are reported. The particles were solidified using 2\% SDS solution. Results demonstrate that increasing the volume of water used for the solvent diffusion by 8 times reduces the solidification time of the PCL within the droplet from approximately 1 hour to a few seconds, due to faster solvent removal. An instantaneous solidification of the droplets was observed when the volume of water was in high excess, 5 to 8 times the theoretical volume. The fast formation of the polymeric crust is of great importance to reduce the loss of the inner aqueous phase during the particle solidification as demonstrated by the analysis of particle morphology reported in Figure 6 . Particles with a porous surface were produced when the lowest volume of water $\left(V_{s d} / V_{t h}=1\right)$ was used for the solidification. This structure was a consequence of the diffusion of water between the outer and inner aqueous phase which occurred when the organic phase was in a semi-solid state for long time. The increase of water volume $\left(V_{s d} / V_{t h}=2.5\right)$ allowed a reduction of the solidification time of the PCL and the formation of 
pores and holes was avoided. However, some cracks and a slight roughness were observed on the surface of the particles because the formation of a polymeric crust at the water/droplet interface was not instantaneous. A further increase of the volume of water $\left(V_{s d} / V_{t h} \geq 5\right)$ provided the production of particles with a dense and smooth surface due to instantaneous solidification of the PCL at the interface which preserved the integrity of the particle avoiding the loss of the inner aqueous phase through the droplets.

\section{ii) Effect of the type of stabilizer}

The effect of the stabilizer type was investigated using different volumes of water $\left(V_{s d} / V_{t h}=1-2.5-5\right)$ in order to evaluate the effect of the stabilizer under different solidification rate conditions of the droplets. SDS (2\%) or PVA (1\%) were used due to their different chemical properties. SDS is an anionic emulsifier with a low molecular weight compared to PVA, which is a viscosity-enhancing stabilizer and a polymer colloid. In Figure 6 the particle morphology observed when the particles were solidified using PVA or SDS as stabilizer and different volumes of water is reported. The morphology of the particles solidified in presence of SDS was discussed previously. In this case, the solidification rate of the PCL was demonstrated to be a key parameter to control the particle morphology as well as to avoid the loss of the inner aqueous phase. The diffusion of the inner aqueous droplets at the water/oil droplet interface cannot be controlled in the presence of SDS and low volume of water $\left(V_{s d} / V_{t h}=1\right)$, due to the absence of a plasticizing layer around the oil droplet. The particles solidified using PVA as stabilizer are characterized by a dense surface without pores no matter what volume of aqueous phase is used for the solidification of the particles. PVA is a surface-active polymer which forms a protective film at the water/oil droplet interface [41]. Thus, the adsorbed PVA polymer layer can slow down the diffusion of water between the external and inner aqueous phase through the organic phase when the solidification of the PCL matrix was carried out in low volume of water $\left(V_{s d} / V_{t h}=1\right)$. This is of great importance for the scaling-up of the process as less volume of water can be used keeping the integrity of particle morphology.

iii) Effect of the volume fraction of the inner aqueous phase $\left(\Phi_{\text {wo }}\right)$ 
Variation of the multicore matrix particle morphology was observed when the volume fraction of the inner aqueous phase ( $\Phi_{\text {wo }}$ ) was increased from 0.10 to 0.15 (Figure 7). The loss of the inner aqueous phase did not occur under these conditions and particles are characterized by a dense polymer surface. However, a further increase of $\Phi_{\text {wo }}$ to 0.3 resulted in the formation of multi-core matrix particles with highly porous surface produced as a result of the water diffusion through the PCL film during the solidification step. Higher amounts of the aqueous phase added to the same volume of organic phase induces coalescence between the outer and inner aqueous phase during solidification of the PCL resulting in the formation of solid particles but with a porous surface.

\section{Encapsulation efficiency of the $W_{1} / O / W_{2}$ emulsion and solidified multi-core matrix particles}

The encapsulation efficiency of copper ions in $\mathrm{W}_{1} / \mathrm{O} / \mathrm{W}_{2}$ emulsion $\left(E E_{W O W}\right)$ was initially measured in order to evaluate the amount of copper ions present in the emulsion prior to the particle formation (solidification).The encapsulation efficiency of copper ions in solid particles $\left(E E_{p}\right)$ was measured in order to investigate the influence of double $\mathrm{W}_{1} / \mathrm{O} / \mathrm{W}_{2}$ emulsion composition (e.g. inner aqueous phase volume fraction) and the solidification conditions (e.g. volume of the aqueous phase and kind of stabilizer used for the emulsion dilution) on the final amount of copper ions present within the particles.

Encapsulation efficiency of copper ions in $\mathrm{W}_{1} / \mathrm{O} / \mathrm{W}_{2}$ emulsion $\left(E E_{\text {WOW }}\right)$ slightly decreased from $97.4( \pm 0.8) \%$ to 93.4 ( \pm 0.2$) \%$ when the volume fraction of the inner aqueous phase $\left(\Phi_{w o}\right)$ increased from 0.1 to 0.3 (Table 1B). Since more aqueous phase is added into the same volume of organic phase, a thinner organic film, acting as a barrier, between the inner and outer aqueous phase is produced and more copper is loss due to diffusion from the droplets.

The increase of the volume fraction of the inner aqueous phase $\left(\Phi_{\text {wo }}\right)$ by three from 0.1 to 0.3 resulted in three times lower copper encapsulation within the particles $\left(E E_{p}\right)$ (Table $\left.1 \mathrm{~B}\right)$. The drug loading of the particles produced with $\Phi_{\text {wo }}$ in a range of 0.1 and 0.3 was almost constant in a range between $4( \pm 0.3) \%$ and $4.5( \pm 0.1) \%$ even though the theoretical drug loading increased from $4.4 \%$ to $11.7 \%$. Two mechanisms can be proposed for the reduction of the encapsulation efficiency and the measured drug loading within the solid particles when the volume fraction of the inner water phase is increased. The first is the increase of the 
concentration gradient of the encapsulated copper ions which is the driving force to induce diffusion of ions into the external aqueous phase during the solidification process [42]. The second mechanism is the partial loss of the inner aqueous phase due to coalescence between the internal and external aqueous phase, which can occur during solidification of PCL. The analysis of the particle morphology discussed previously confirmed that the partial loss of the inner aqueous phase seems to be involved in the loss of copper ions from the particles produced with $\Phi_{\text {wo }}=0.3$, as demonstrated by the porous surface of the particle. On the contrary, the lack of porous surface of the particles produced with $\Phi_{\text {wo }}=0.15$ confirmed that the lower encapsulation efficiency is mainly due to the enhanced diffusion of copper caused by the higher concentration gradient rather than the loss of the inner aqueous phase.

Table $1(\mathrm{~A})$ reports the encapsulation efficiency $\left(E E_{p}\right)$ and drug loading $(D L)$ of the solidified particles as a function of the volume of water used for the solvent diffusion and the kind of stabilizer (SDS or PVA). Results demonstrate that using SDS as stabilizer and increasing the volume of water by 8 times increases the encapsulation efficiency of copper ions 3 times while the drug loading increases 4 times. The low encapsulation efficiency observed when the solidification of PCL was slow $\left(V_{s d} / V_{t h}=1\right)$ is related to the loss of the inner aqueous phase due to coalescence of the inner and outer aqueous phase as demonstrated by the formation of particles with a porous surface discussed previously. Increasing $V_{s d}$ to 5 and 8 times the theoretical volume achieves the highest encapsulation efficiency of copper ions, due to the instantaneous solidification of the PCL matrix. This is in accordance with the analysis of particle morphology, Figure 6.

Encapsulation efficiency of copper ions within the particles solidified using PVA as stabilizer was constant at $99( \pm 1) \%$ no matter the volume of water used for the solidification (Table $1 \mathrm{~A})$. Particles had a smooth surface (Figure 6) and high encapsulation was in accordance with the previous findings. Rainer et al. [43] and Yang et al. [44] also observed an increase of the encapsulation efficiency of hydrophilic compounds with an increase of PVA concentration in the aqueous phase.

The encapsulation efficiency of $\alpha$-tocopherol in the solidified particles, was not influenced by the process conditions studied due to its insolubility in water. Thus, $\alpha$-tocopherol could be entrapped efficiently into the hydrophobic PCL matrix with an encapsulation efficiency of $93( \pm 6.7) \%$ and a drug loading of $1.5( \pm 0.2) \%$ (Table 1A). 


\section{Conclusions}

The results obtained demonstrate that the method used to produce the $\mathrm{W} / \mathrm{O} / \mathrm{W}$ emulsion (membrane emulsification) followed by solvent diffusion can be successfully applied for the production of highly uniform multicore particles between 40 and $120 \mu \mathrm{m}$ with a hydrophobic poly-caprolactone matrix. The process was scaled up using a novel azimuthal oscillating membrane emulsification system while the uniformity and the morphology of the particles were maintained. Simultaneous encapsulation of hydrophilic (copper ions up to 99\%) and hydrophobic molecules ( $\alpha$-tocopherol up to 93\%) was achieved. It was possible to increase the encapsulation of hydrophilic molecule either using the fast solidification of the PCL or using the PVA as stabilizer dissolved in the aqueous phase during the solidification step. Fish gelatin was used to stabilize the internal water droplets and prevent the coalescence.

The multicore-matrix particles produced in this study could be used for the encapsulation of practical drug systems, such as hydrophilic doxorubicin and hydrophobic paclitaxel for cancer treatment [45], hydrophilic folic acid and hydrophobic methotrexate for Rheumatoid Arthritis treatment [46], hydrophilic ampicillin and rosemary extract (containing hydrophobic carnosic acid and carnosol) as effective treatment of penicillin resistant Staphylococcus aureus bacteria [47] and our future work will be focused on the study of the such drug systems.

\section{Acknowledgements}

The authors gratefully acknowledge the financial support of PON OLIO PIU' 01_545 'Sistemi tecnologici avanzati e processi integrati della filiera olivicola per la valorizzazione dei prodotti e dei sottoprodotti, lo sviluppo di nuovi settori e la creazione di sistemi produttivi Eco-compatibili 


\section{References}

[1] H.-J. Huang, W.-K. Yuan, and X. D. Chen, "Microencapsulation Based on Emulsification for Producing Pharmaceutical Products: A Literature Review,” Dev. Chem. Eng. Miner. Process., vol. 14, no. 3-4, pp. 515-544, May 2008.

[2] N. J. Zuidam and E. Shimoni, "Overview of Microencapsulates for Use in Food Products or Processes and Methods to Make Them,” pp. 3-30, 2010.

[3] M. A. Woodruff and D. W. Hutmacher, "The return of a forgotten polymer - Polycaprolactone in the 21st century,” Prog. Polym. Sci., vol. 35, pp. 1217-1256, 2010.

[4] a. a. Karim and R. Bhat, "Fish gelatin: properties, challenges, and prospects as an alternative to mammalian gelatins,” Food Hydrocoll., vol. 23, no. 3, pp. 563-576, May 2009.

[5] G. R. Zimmermann, J. Lehár, and C. T. Keith, "Multi-target therapeutics: when the whole is greater than the sum of the parts.,” Drug Discov. Today, vol. 12, no. 1-2, pp. 34-42, Jan. 2007.

[6] J. Jia, F. Zhu, X. Ma, Z. Cao, Y. Li, and Y. Z. Chen, "Mechanisms of drug combinations: interaction and network perspectives.,” Nat. Rev. Drug Discov., vol. 8, pp. 111-128, 2009.

[7] B. Wang, W. Jiang, H. Yan, X. Zhang, L. Yang, L. Deng, G. K. Singh, and J. Pan, "Novel PEG-graftPLA nanoparticles with the potential for encapsulation and controlled release of hydrophobic and hydrophilic medications in aqueous medium.,” Int. J. Nanomedicine, vol. 6, pp. 1443-1451, 2011.

[8] M. Hombreiro Pérez, C. Zinutti, A. Lamprecht, N. Ubrich, A. Astier, M. Hoffman, R. Bodmeier, and P. Maincent, "The preparation and evaluation of poly(epsilon-caprolactone) microparticles containing both a lipophilic and a hydrophilic drug.,” J. Control. Release, vol. 65, no. 3, pp. 429-38, Apr. 2000.

[9] M. Windbergs, Y. Zhao, J. Heyman, and D. a Weitz, "Biodegradable core-shell carriers for simultaneous encapsulation of synergistic actives.,” J. Am. Chem. Soc., vol. 135, no. 21, pp. 7933-7, May 2013.

[10] H. Zhang, G. Wang, and H. Yang, "Drug delivery systems for differential release in combination therapy.,” Expert Opin. Drug Deliv., vol. 8, no. 2, pp. 171-90, Feb. 2011.

[11] N. V. N. Jyothi, P. M. Prasanna, S. N. Sakarkar, K. S. Prabha, P. S. Ramaiah, and G. Y. Srawan, "Microencapsulation techniques, factors influencing encapsulation efficiency.," J. Microencapsul., vol. 27, no. 3, pp. 187-97, May 2010.

[12] R. Arshady, "Microspheres and Microcapsules, a Survey of Manufacturing Techniques Part II : Coacervation,” Polym. Eng. Sci., vol. 30, no. 15, pp. 905-914, 1990.

[13] A. J. P. Van Zyl, R. D. Sanderson, D. De Wet-Roos, and B. Klumperman, "Core/shell particles containing liquid cores: Morphology prediction, synthesis, and characterization,” Macromolecules, vol. 36, pp. 8621-8629, 2003.

[14] P. Couvreur, M. J. Blanco-Prieto, F. Puisieux, B. Roques, and E. Fattal, "Multiple emulsion technology for the design of microspheres containing peptides and oligopeptides," Adv. Drug Deliv. Rev., vol. 28, pp. 85-96, 1997. 
[15] C. Schugens, N. Laruelle, N. Nihant, C. Grandfils, R. Jkrome, and P. Teyssi, "Effect of the emulsion stability on the morphology and porosity of semicrystalline poly-lactide microparticles prepared by w / o / w double emulsion-evaporation,” J. Control. Release, vol. 32, no. 94, pp. 161-176, 1994.

[16] S. Benita, “Microencapsulation.Methods and Industrial Application,” in New York, vol. 158, no. 8, 2006.

[17] G. T. Vladisavljević, I. Kobayashi, and M. Nakajima, "Production of uniform droplets using membrane, microchannel and microfluidic emulsification devices," Microfluid. Nanofluidics, vol. 13, no. 1, pp. 151-178, Feb. 2012.

[18] L. Giorno, G. De Luca, A. Figoli, E. Piacentini, and E. Drioli, "Membrane Emulsification : Principles and Applications," in Wiley, no. 2009, 2009, pp. 463-494.

[19] C. Charcosset, "Preparation of emulsions and particles by membrane emulsification for the food processing industry,” J. Food Eng., vol. 92, no. 3, pp. 241-249, Jun. 2009.

[20] G. T. Vladisavljević and R. a Williams, "Recent developments in manufacturing emulsions and particulate products using membranes.,” Adv. Colloid Interface Sci., vol. 113, no. 1, pp. 1-20, Mar. 2005.

[21] M. Nakajima, “( 12 ) United States Patent U . S . Patent,” vol. 1, no. 12, pp. 0-6, 2003.

[22] C. Charcosset, Membrane Processes in Biotechnologies and Pharmaceutics. Elsevier, 2012.

[23] W. Liu, X.-L. Yang, and W. S. W. Ho, "Preparation of uniform-sized multiple emulsions and micro/nano particulates for drug delivery by membrane emulsification.,” J. Pharm. Sci., vol. 100, no. 1, pp. 75-93, Jan. 2011.

[24] E. Piacentini, L. Giorno, M. M. Dragosavac, G. T. Vladisavljević, and R. G. Holdich, "Microencapsulation of oil droplets using cold water fish gelatine/gum arabic complex coacervation by membrane emulsification,” Food Res. Int., vol. 53, no. 1, pp. 362-372, Aug. 2013.

[25] J. Wu, Q. Fan, Y. Xia, and G. Ma, "Uniform-sized particles in biomedical field prepared by membrane emulsification technique," Chem. Eng. Sci., 2014.

[26] Y. Byun, J. B. Hwang, S. H. Bang, D. Darby, K. Cooksey, P. L. Dawson, H. J. Park, and S. Whiteside, "Formulation and characterization of a-tocopherol loaded poly -caprolactone (PCL) nanoparticles,” LWT - Food Sci. Technol., vol. 44, pp. 24-28, 2011.

[27] A. Imbrogno, E. Piacentini, E. Drioli, and L. Giorno, "Preparation of uniform poly-caprolactone Microparticles by membrane emulsi fi cation / solvent diffusion process,” vol. 467, pp. 262-268, 2014.

[28] M. Bonnet, M. Cansell, F. Placin, M. Anton, and F. Leal-Calderon, "Impact of sodium caseinate concentration and location on magnesium release from multiple W/O/W emulsions," Langmuir, vol. 26, no. 21, pp. 9250-9260, 2010.

[29] M. M. Dragosavac, R. G. Holdich, G. T. Vladisavljević, and M. N. Sovilj, "Stirred cell membrane emulsification for multiple emulsions containing unrefined pumpkin seed oil with uniform droplet size,” J. Memb. Sci., vol. 392-393, pp. 122-129, 2012.

[30] M. D. Dubbs and R. B. Gupta, "Solubility of vitamin E (alpha-tocopherol) and vitamin K-3 (menadione) in ethanol-water mixture,” J. Chem. Eng. Data, vol. 43, no. 98, pp. 590-591, 1998. 
[31] S. R. Kosvintsev, G. Gasparini, R. G. Holdich, I. W. Cumming, and M. T. Stillwell, "Liquid - Liquid Membrane Dispersion in a Stirred Cell with and without Controlled Shear,” Ind. Eng. Chem. Res., pp. 9323-9330, 2005.

[32] M. T. Stillwell, R. G. Holdich, S. R. Kosvintsev, G. Gasparini, and I. W. Cumming, "Stirred Cell Membrane Emulsification and Factors Influencing Dispersion Drop Size and Uniformity,” Ind. Eng. Chem. Res., vol. 46, no. 3, pp. 965-972, Jan. 2007.

[33] R. G. Holdich, M. M. Dragosavac, G. T. Vladisavljevic, and E. Piacentini, "Continuous Membrane Emulsifi cation with Pulsed ( Oscillatory ) Flow,” Ind. Eng. Chem. Res., vol. 52, pp. 507-515, 2013.

[34] V. Schro, "Production of emulsions using microporous, ceramic membranes," Colloids Surfaces A Physicochem. Eng. Asp., vol. 152, pp. 103-109, 1999.

[35] K. . W. and K. Lunkenheimer, "Determination of the surface tension of surfactant solutions applying the method of Lecomte du Noiiy (ring tensiometer),” Colloid Polym. Sci., vol. 259, pp. 354-366, 1989.

[36] V. G. Babak, F. Baros, O. Boulanouar, F. Boury, M. Fromm, N. R. Kildeeva, N. Ubrich, and P. Maincent, "Impact of bulk and surface properties of some biocompatible hydrophobic polymers on the stability of methylene chloride-in-water mini-emulsions used to prepare nanoparticles by emulsification-solvent evaporation.," Colloids Surf. B. Biointerfaces, vol. 59, no. 2, pp. 194-207, Oct. 2007.

[37] J. Surh, E. Decker, and D. Mcclements, "Properties and stability of oil-in-water emulsions stabilized by fish gelatin,” Food Hydrocoll., vol. 20, no. 5, pp. 596-606, Jul. 2006.

[38] C. H. Villa, L. B. Lawson, Y. Li, and K. D. Papadopoulos, "Internal coalescence as a mechanism of instability in water-in-oil-in-water double-emulsion globules,” Langmuir, vol. 19, no. 13, pp. 244249, 2003.

[39] M. M. Dragosavac, M. N. Sovilj, S. R. Kosvintsev, R. G. Holdich, and G. T. Vladisavljević, "Controlled production of oil-in-water emulsions containing unrefined pumpkin seed oil using stirred cell membrane emulsification,” J. Memb. Sci., vol. 322, no. 1, pp. 178-188, Sep. 2008.

[40] M. Pathak, "Numerical simulation of membrane emulsification: Effect of flow properties in the transition from dripping to jetting,” J. Memb. Sci., vol. 382, no. 1-2, pp. 166-176, Oct. 2011.

[41] J. R. F. Boury, Tz. Ivanova, I. Panaïotov, J.E. Proust, A. Bois, "Dynamic Properties of Poly(DLlactide) and Polyvinyl Alcohol Monolayers at the Air/Water and Dichloromethane/Water Interfaces," J. Colloid Interface Sci., vol. 169, pp. 380-392, 1995.

[42] R. Liu, S.-S. Huang, Y.-H. Wan, G.-H. Ma, and Z.-G. Su, "Preparation of insulin-loaded PLA/PLGA microcapsules by a novel membrane emulsification method and its release in vitro.," Colloids Surf. B. Biointerfaces, vol. 51, no. 1, pp. 30-8, Aug. 2006.

[43] R. Alex and R. Bodmeier, "Encapsulation of water-soluble drugs by a modified solvent evaporation method. I. Effect of process and formulation variables on drug entrapment.," J. Microencapsul., vol. 7, no. 3, pp. 347-55, 1990.

[44] Y. Y. Yang, T. S. Chung, and N. P. Ng, "Morphology, drug distribution, and in vitro release profiles of biodegradable polymeric microspheres containing protein fabricated by double-emulsion solvent extraction/evaporation method.," Biomaterials, vol. 22, no. 3, pp. 231-41, Feb. 2001. 
[45] H. Gogas, C. Papadimitriou, H. P. Kalofonos, D. Bafaloukos, G. Fountzilas, D. Tsavdaridis, A. Anagnostopoulos, A. Onyenadum, P. Papakostas, T. Economopoulos, C. Christodoulou, P. Kosmidis, and C. Markopoulos, "Neoadjuvant chemotherapy with a combination of pegylated liposomal doxorubicin (Caelyx) and paclitaxel in locally advanced breast cancer: A phase II study by the Hellenic Cooperative Oncology Group,” Ann. Oncol., vol. 13, pp. 1737-1742, 2002.

[46] A. T. Borchers, C. L. Keen, G. S. Cheema, and M. E. Gershwin, "The use of methotrexate in rheumatoid arthritis,” Semin. Arthritis Rheum., vol. 34, no. 1, pp. 465-483, 2004.

[47] S. Hemaiswarya, A. K. Kruthiventi, and M. Doble, "Synergism between natural products and antibiotics against infectious diseases,” Phytomedicine, vol. 15, pp. 639-652, 2008. 


\section{List of Figures}

Figure 1 Dispersion Cell equipment scheme. 1-syringe pump; 2-injection chamber; 3-glass cylinder; 4-stainless steel stirrer with a blade at the bottom ending; 5-voltage regulator. Azimuthally oscillating system equipment scheme. 1-syringe pump containing the dispersed phase; 2continuous phase tank; 3- membrane module; 4-servo motor; 5-emulsion tank; 6-control panel. $\phi_{W O}$ : volume fraction of the inner aqueous phase; $\phi_{W O W}$ : volume fraction of the dispersed phase (W/O); $J_{D P}$ : injection flux; $\tau$.shear stress.

Figure 2 (A) Effect of injection flux on droplet size and size distribution of $\mathrm{O} / \mathrm{W}$ emulsion at constant shear stress (8 Pa). (B) Effect of shear stress on droplet size and size distribution of $\mathrm{O} / \mathrm{W}$ emulsion at constant injection flux of $216 \mathrm{~L} \mathrm{~h}^{-1} \mathrm{~m}^{-2}$. Produced using Dispersion Cell. (mean \pm $S D, \mathrm{n}=3)$

Figure 3 Images of double $\mathrm{W}_{1} / \mathrm{O} / \mathrm{W}_{2}$ emulsion with different concentration of PCL in the organic phase. (Double emulsion composition: $W_{1}=5 \%$ fish gelatin; $O=\mathrm{PCL}$ in DCM; $W_{2}=1 \%$ PVA)

Figure 4 (A) Mean droplet size and size distribution of simple O/W as a function of shear stress (1-6 Pa) and injection flux of 12 and $46 \mathrm{~L} \mathrm{~h}^{-1} \mathrm{~m}^{-2}$ (mean $\pm S D, \mathrm{n}=3$ ). (B) Photographs of $\mathrm{O} / \mathrm{W}$ emulsion produced at different shear stress keeping the injection flux constant at $12 \mathrm{~L} \mathrm{~h}^{-1} \mathrm{~m}^{-2}$ and produced using Azimuthally oscillating system.

Figure 5 Mean droplet size and size distribution of double $\mathrm{W}_{1} / \mathrm{O} / \mathrm{W}_{2}$ emulsion $\left(W_{1}=5 \% \mathrm{FG} ; O=30 \%\right.$ PCL, $W_{2}=1 \%$ PVA, $\phi_{W O}=0.1$ ) as a function of the dispersed phase flux keeping the shear stress at $5 \mathrm{~Pa}$ and increasing the injection flux in a range of 23 to $216 \mathrm{~L} \mathrm{~h}^{-1} \mathrm{~m}^{-2} ; \% \mathrm{v} / \mathrm{v}$ is the content of the dispersed phase in the emulsion. (mean $\pm S D$, $\mathrm{n}=3$ )

Figure 6 SEM photographs of multi-core matrix particles produced with different ratio between the used $\left(V_{s d}\right)$ and the theoretical volume $\left(V_{t h}\right)$ and different stabilizer (PVA and SDS).

Figure 7 SEM photographs of multi-core matrix particles produced with different volume fraction of inner aqueous phase $\left(\phi_{W O}\right)$. Solidification conditions: $V_{s d} / V_{t h}=5$ and $2 \%$ SDS. 


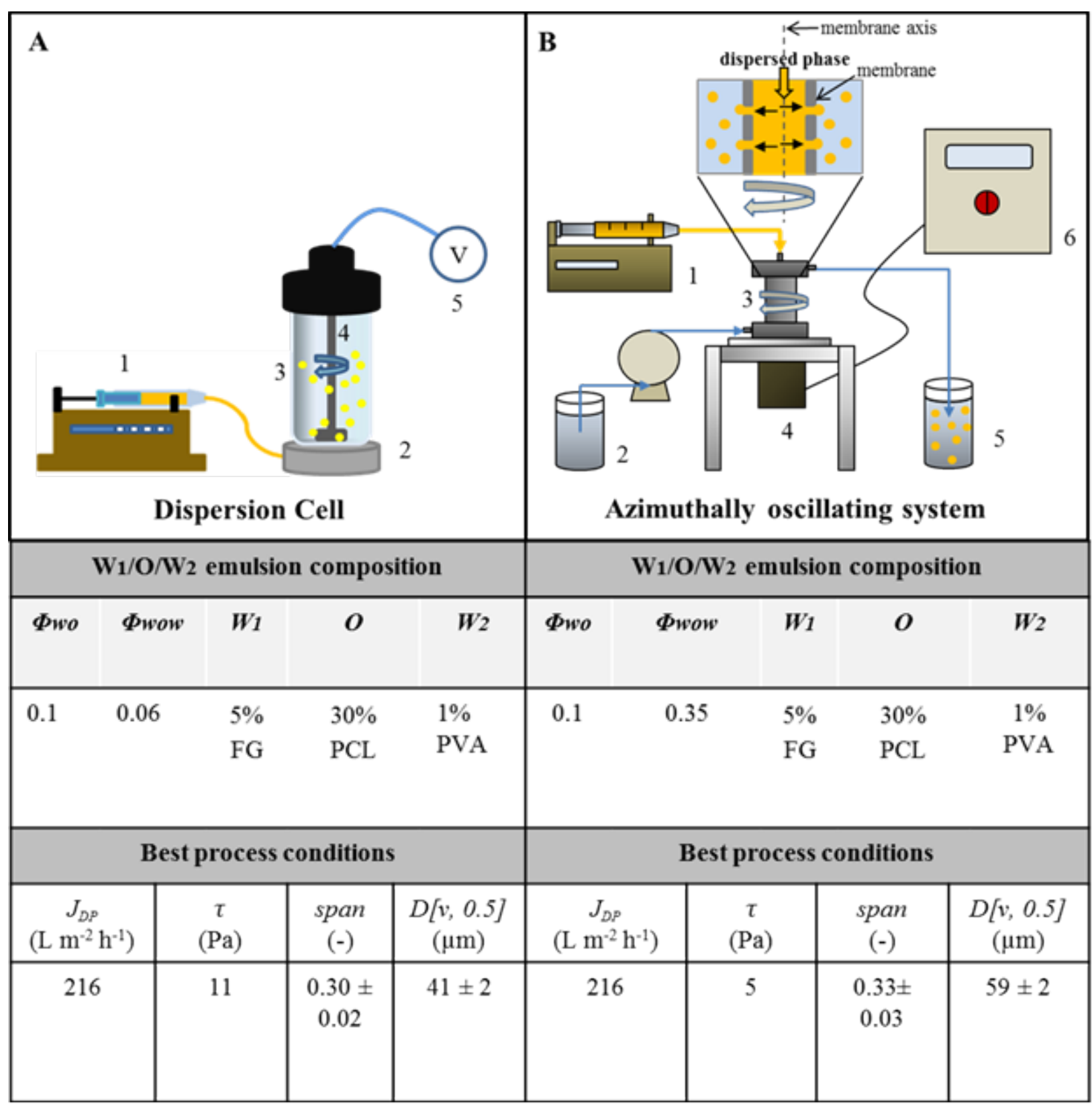

Figure 1 

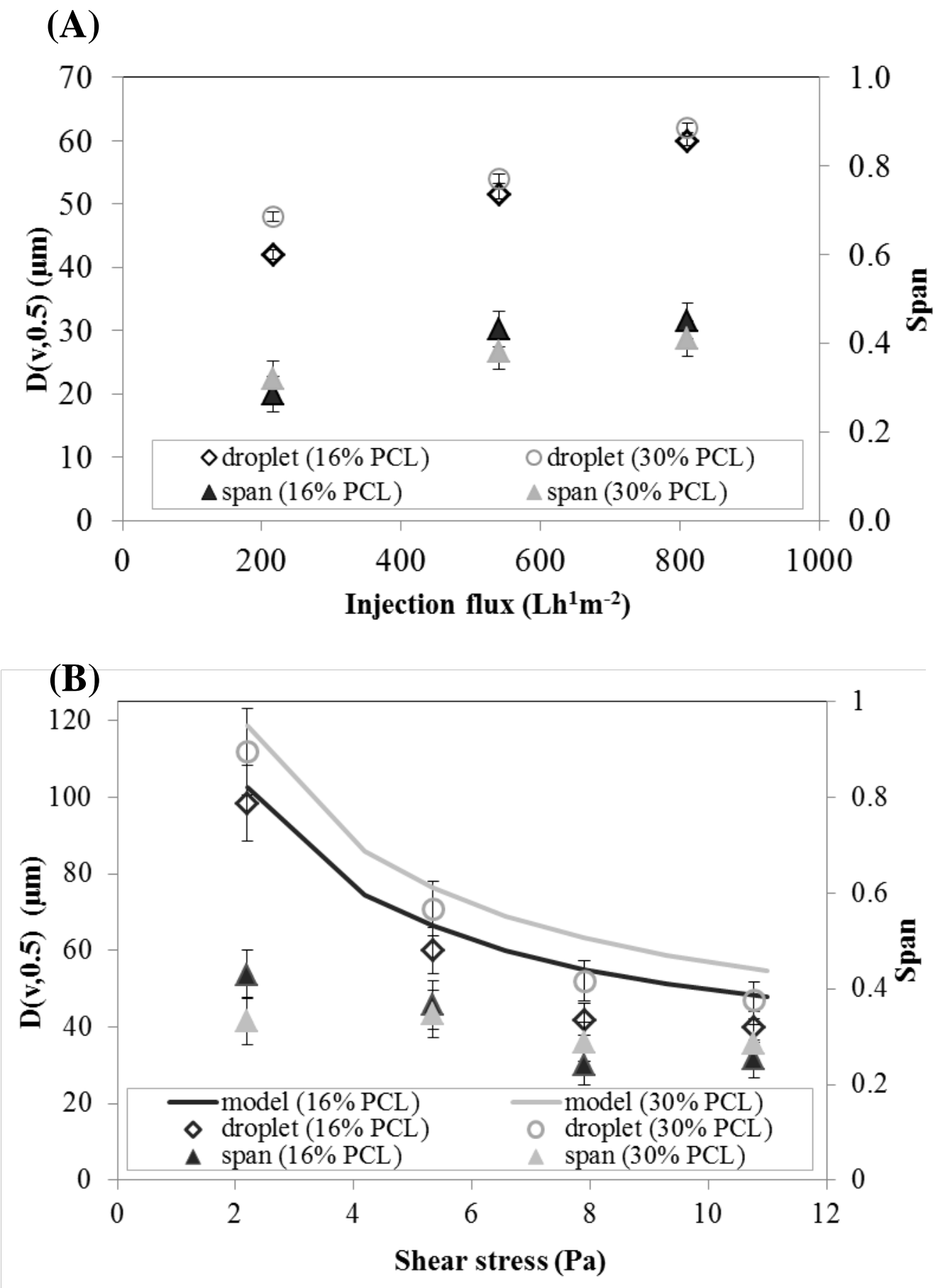

Figure 2 


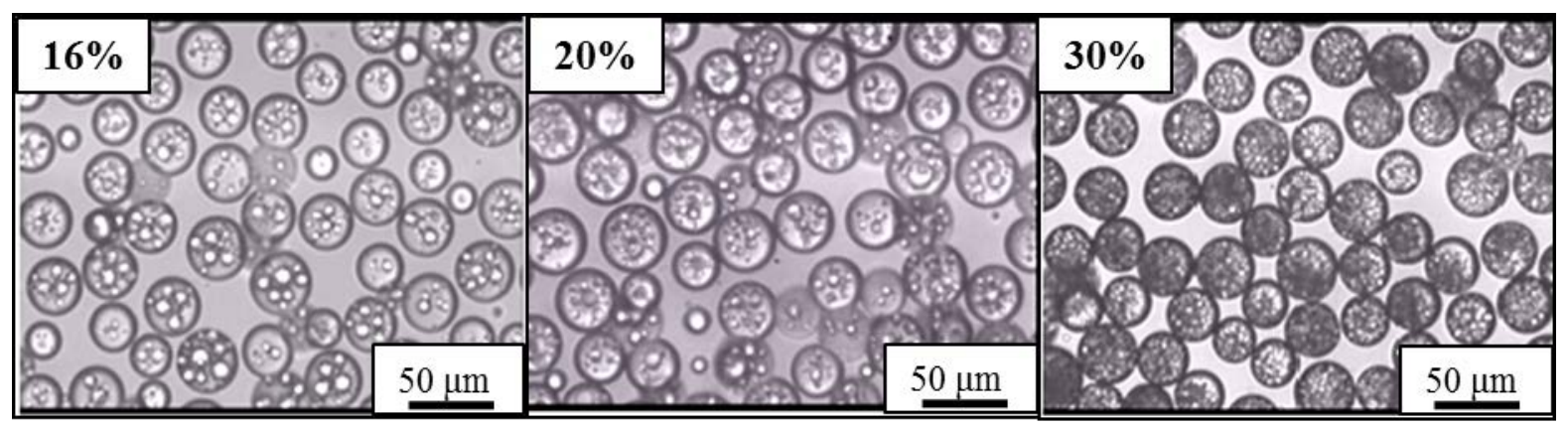

Figure 3 
(A)

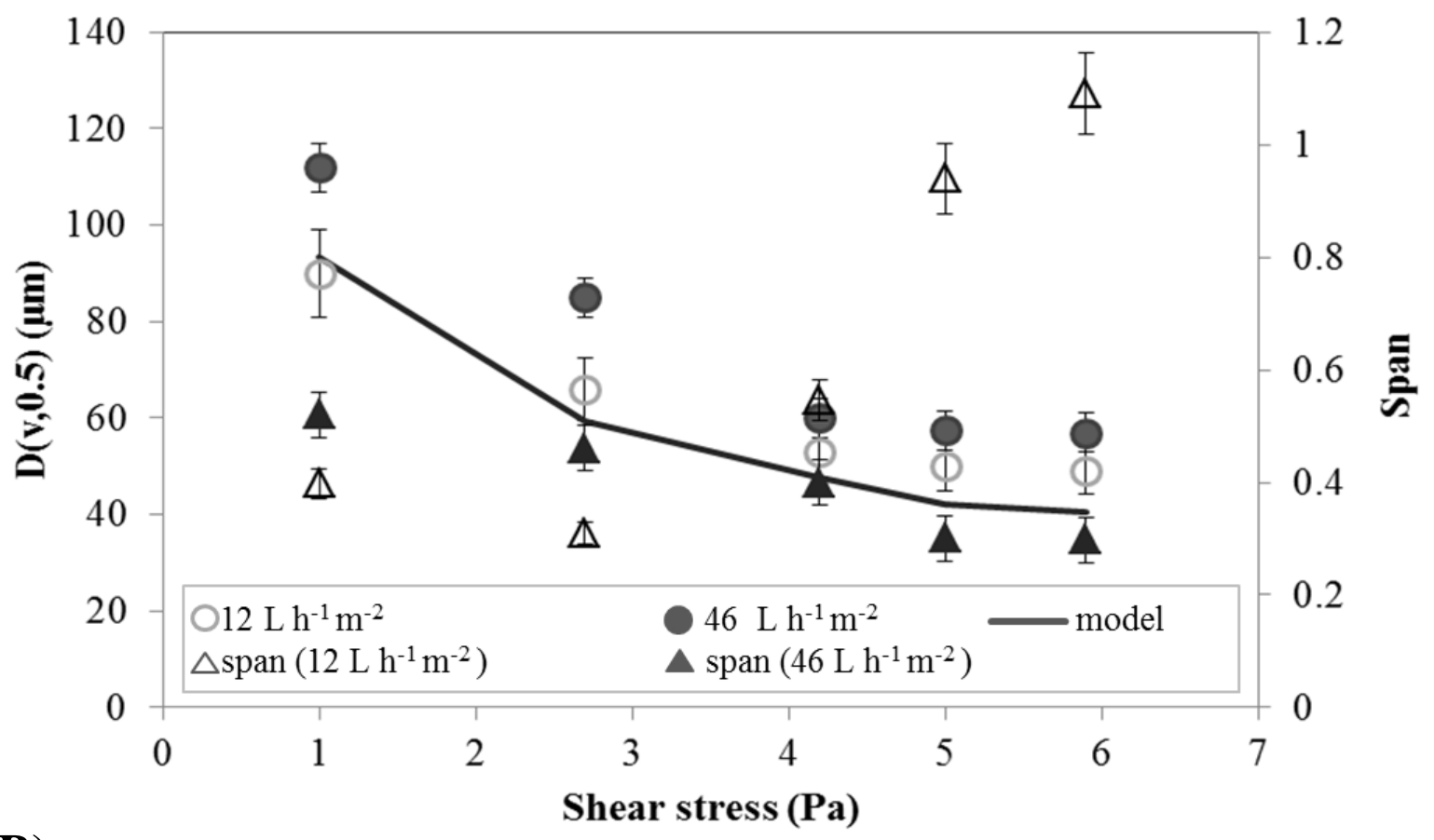

(B)

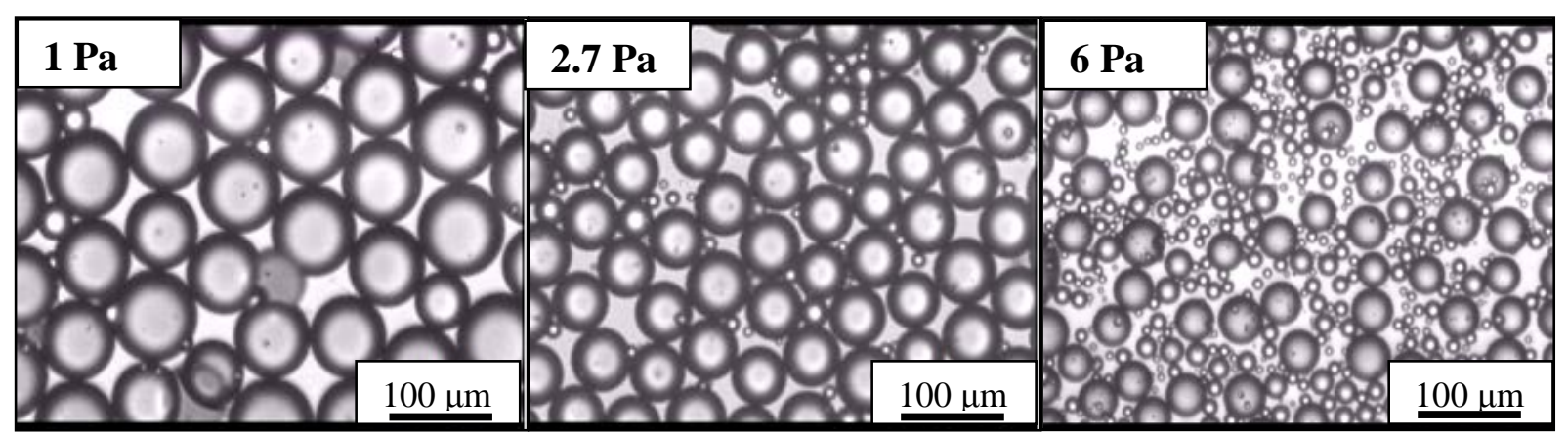

Figure 4 


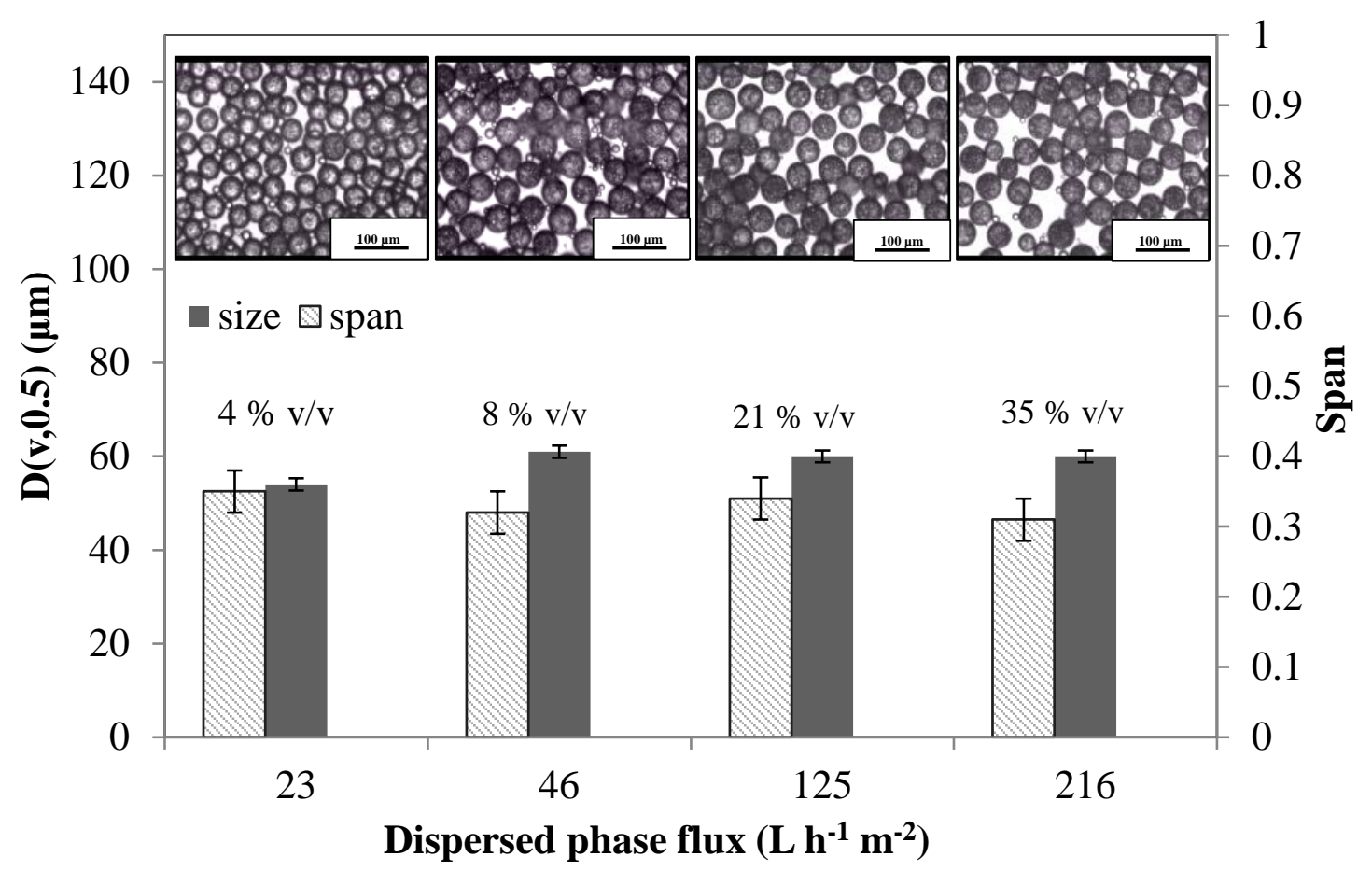

Figure 5 


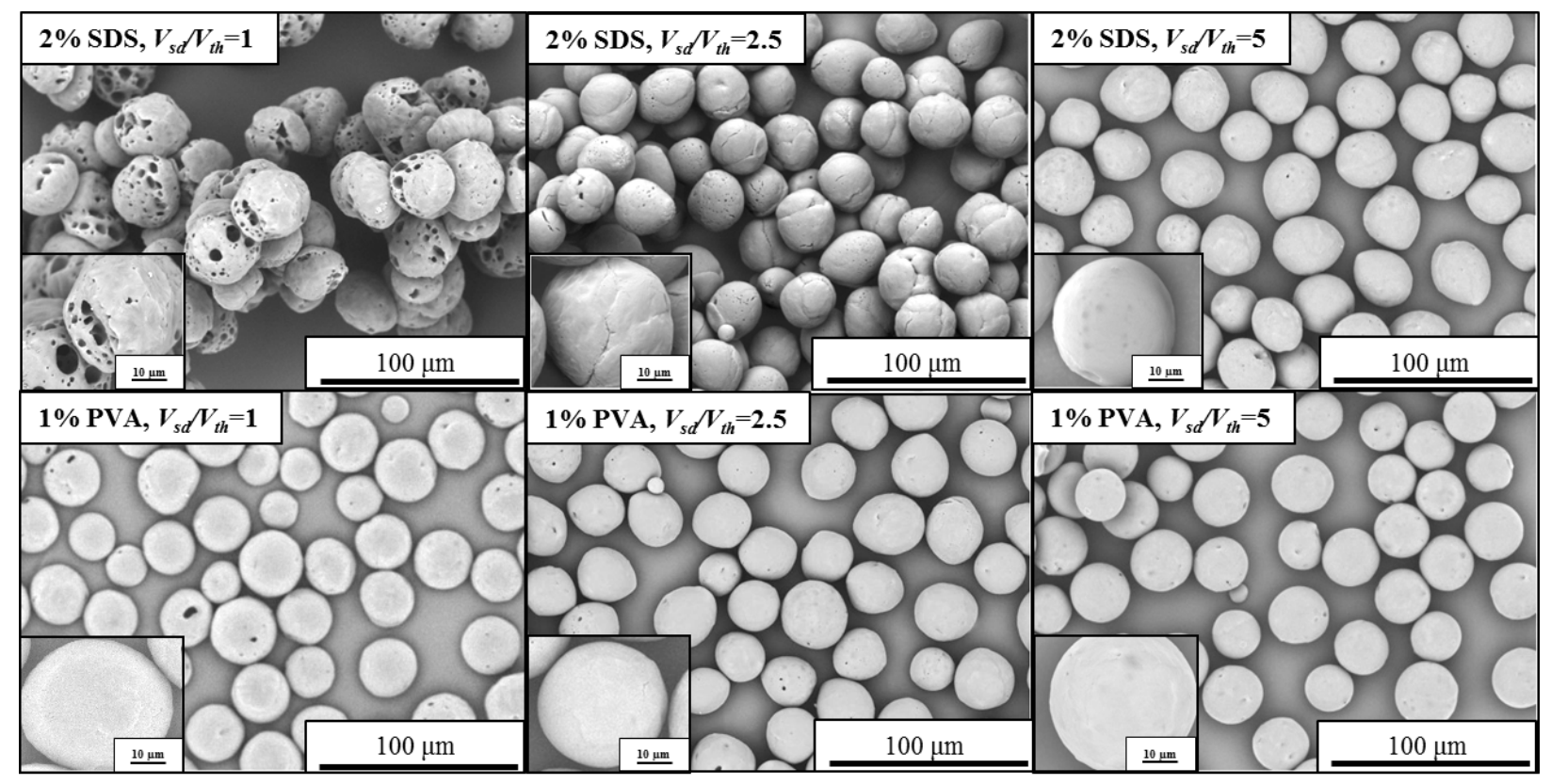

Figure 6 


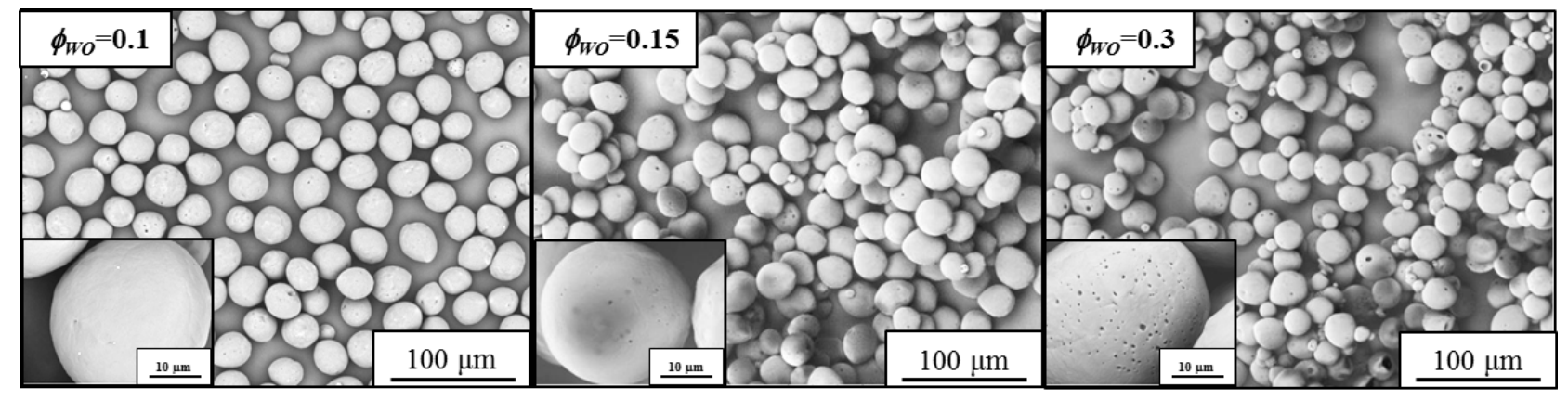

Figure 7 
Table 1. (A) Experimental conditions, encapsulation efficiency of double emulsion ( $\left.E_{\text {wow }}\right)$, encapsulation efficiency $\left(E E_{p}\right)$, and drug loading $(D L)$ of solid particles produced with different $V_{s d} / V_{\text {th }}$ ratio. (B) $E_{\text {wow }}$, $E E_{p}$ and $D L$ at different volume fraction of aqueous phase $\left(\Phi_{\text {wo }}\right), V_{s d}$-Volume used; $V_{t h}$ - theoretic volume; $\Phi$ volume fraction; (mean $\pm S D$, $\mathrm{n}=3$ ).

(A)

SDS

$E E_{\text {wow }}(\%)$

$\mathrm{Cu}(\mathrm{II})$

time

(minutes) $\quad\left(\Phi_{w o}=0.1\right)$
PVA

$V_{s d}[\mathrm{~L}] \quad V_{s d} / V_{t h}$

Droplet

$\mathrm{Cu}(\mathrm{II})$
$E E_{p}(\%)$

$D L(\%)$

$\alpha-$ tocopherol tocopherol

\begin{tabular}{llllllllll}
\hline 0.3 & 1 & 60 & $97.4( \pm 0.8)$ & $29.6( \pm 5.3)$ & $1.3( \pm 0.3)$ & $99( \pm 1)$ & $4.4( \pm 0.1)$ & $97( \pm 2)$ & $1.6( \pm 0.2)$ \\
\hline 0.75 & 2.5 & 15 & $97.4( \pm 0.8)$ & $77.5( \pm 3.6)$ & $3.5( \pm 0.2)$ & $98( \pm 2)$ & $4.3( \pm 0.2)$ & $85( \pm 5)$ & $1.4( \pm 0.3)$
\end{tabular}

1.5

instantaneous

$97.4( \pm 0.8) \quad 91.5( \pm 6)$

$4.4( \pm 0.2)$

$99( \pm 1)$

$4.4( \pm 0.1)$

$90( \pm 7)$

$1.5( \pm 0.3)$

2.4

instantaneous

$97.4( \pm 0.8)$

$95.5( \pm 4)$

$4.4( \pm 0.2)$

99( \pm 1$)$

$4.4( \pm 0.1)$

$98( \pm 1)$

$1.6( \pm 0.2)$ 
(B)

\begin{tabular}{|c|c|c|c|c|c|c|c|}
\hline \multirow[t]{2}{*}{$\boldsymbol{\Phi}_{\text {wo }}$} & \multirow[t]{2}{*}{$\boldsymbol{\Phi}_{\text {wow }}$} & \multirow[t]{2}{*}{$V_{s d} / V_{t h}$} & \multirow[t]{2}{*}{$\begin{array}{c}E E_{\text {wow }}(\%) \\
\operatorname{Cu}(\mathrm{II})\end{array}$} & \multirow[t]{2}{*}{$\begin{array}{c}E E_{p}(\%) \\
\operatorname{Cu}(\mathrm{II})\end{array}$} & \multirow{2}{*}{$\begin{array}{c}E E_{p}(\%) \\
\alpha- \\
\text { tocopherol }\end{array}$} & \multicolumn{2}{|c|}{$\begin{array}{c}D L \% \\
\mathrm{Cu}(\mathrm{II})\end{array}$} \\
\hline & & & & & & measured & Theoretical \\
\hline 0.1 & 0.06 & 5 & $97.4( \pm 0.8)$ & $95.5( \pm 4)$ & $99( \pm 1)$ & $4.4( \pm 0.2)$ & 4.4 \\
\hline 0.15 & 0.06 & 5 & $97.0( \pm 0.3)$ & $65.3( \pm 1)$ & $95.8( \pm 6)$ & $4.3( \pm 0.2)$ & 7 \\
\hline 0.3 & 0.06 & 5 & $93.4( \pm 0.2)$ & $32( \pm 6)$ & $99( \pm 1)$ & $4.2( \pm 0.2)$ & 11.7 \\
\hline
\end{tabular}

